\title{
Frequency and Genotyping of Acanthamoeba Species in the Swimming Pools and Ponds of Khoramabad, Iran, in 2016
}

\author{
Majid Faraji ${ }^{1}$, Amirhossein Maghsood ${ }^{2}$, Shirzad Fallahi ${ }^{3}$, Ali Chegeni Sharafi ${ }^{4}$, Azadeh Karimi ${ }^{4}$, \\ Zohreh Lasjerdi ${ }^{5}$, Mohammad Fallah ${ }^{6, *}$ \\ ${ }^{1}$ MSc in Parasitology, Hamadan University of Medical Sciences, Hamadan, Iran \\ ${ }^{2}$ Associate Professor, Department of Parasitology, School of Medicine, Hamadan University of Medical Sciences, Hamadan, Iran \\ ${ }^{3}$ Assistant Professor, Department of Parasitology, School of Medicine, Lorestan University of Medical Sciences, Khoramabad, Iran \\ ${ }^{4}$ MSc in Parasitology, Lorestan University of Medical Sciences, Khoramabad, Iran \\ ${ }^{5}$ MSc in Parasitology, Shahid Beheshti University of Medical Sciences, Tehran, Iran \\ ${ }^{6}$ Professor, Department of Parasitology, School of Medicine, Hamadan University of Medical Sciences, Hamadan, Iran
}

* Corresponding Author: Mohammad Fallah, Department of Parasitology, School of Medicine, Hamadan University of Medical Sciences, Hamadan, Iran.Email:fallah@umsha.ac.ir

Received: 14.05 .2017

Accepted: 10.09 .2017

How to Cite this Article: Faraji M, Maghsood A, Fallahi Sh, Chegeni Sharafi A, Karimi A, Lasjerdi Z, Fallah M. Frequency and Genotyping of Acanthamoeba Species in the Swimming Pools and Ponds of Khoramabad, Iran, in 2016. Sci J Hamadan Univ Med Sci. 2017;24(3): 236-243 DOI: $10.18869 /$ acadpub.ajcm. 24.3.236.

\section{Abstract}

Background and Objective: Acanthamoeba is a free-living and opportunistic amoeba found in the water, soil, and air. This amoeba causes granulomatous amoebic encephalitis in the immunocompromised patients and amoebic keratitis in the people using contact lenses. The genotypes of Acanthamoeba are pathogenic and non-pathogenic. Regarding this, the present study aimed to determine the frequency and genotypes of Acanthamoeba in the water pools and ponds of Khorramabad, Iran, using culture, polymerase chain reaction (PCR), and sequencing methods in 2016.

Materials and Methods: This study was conducted on a total of 84 water samples collected from the water pools and ponds of Khorramabad. The samples were filtered using nitrocellulose syringe $(0.45 \mu \mathrm{m})$; subsequently, they were cultured on $1.5 \%$ non-nutrient agar, covered by killed Escherichia coli and incubated at $27^{\circ} \mathrm{C}$. After the extraction of DNA from positive samples, PCR was performed using specific primers to detect and confirm Acanthamoeba. Then, for genotyping, the PCR products of positive samples were sequenced.

Results: Out of the 84 water samples, $50(59.5 \%)$ cases were positive for amoeba in the culture method. However, the results of the PCR revealed 35 (41.7\%) positive samples for Acanthamoeba. The sequencing of the PCR products demonstrated that 17 samples were $T 4$ genotype (pathogen), and the rest were other Acanthamoeba genotypes.

Conclusion: This study indicated the high prevalence of Acanthamoeba species, especially the pathogenic type, in the water pools of Khoramabad that could be a source of infection risk for humans. Regarding the fact that almost half of the found genotypes were pathogenic (genotype T4) that are the main cause of amoebic keratitis, these water bodies could be a potential risk factor for the public health. Therefore, the health professionals should prevent contamination.

Keywords: Acanthamoeba; Genotype; Polymerase Chain Reaction; Water 
dof: 10.18869 /acadpub.ajcm.24.3.236

مقاله يخوهشى

\title{
فراوانى كونه هاى آكانتامبا در آب استخر ها و حوضجه هاى شهر خرم آباد و تعيين زنوثي هاى آن درسال هو
}

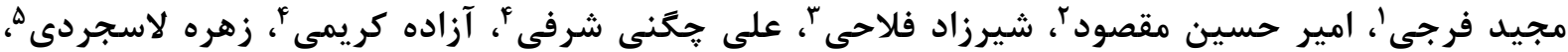 محمد فلاح \&."}

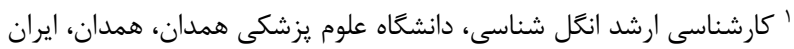

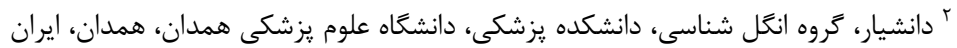

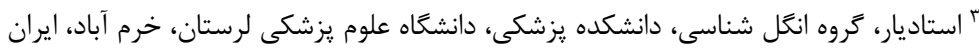

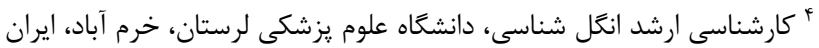

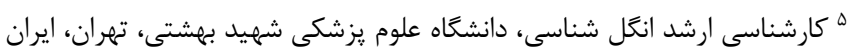

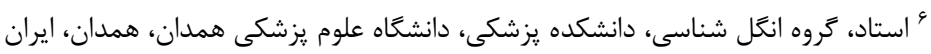
" * يسنده مسئول: محمد فلاح، كروه انغل شناسى، دانشكده يزشكى، دانشكاه علوم يزشكى همدان، همدان، ايران. fallah@umsha.ac.ir ايميل:

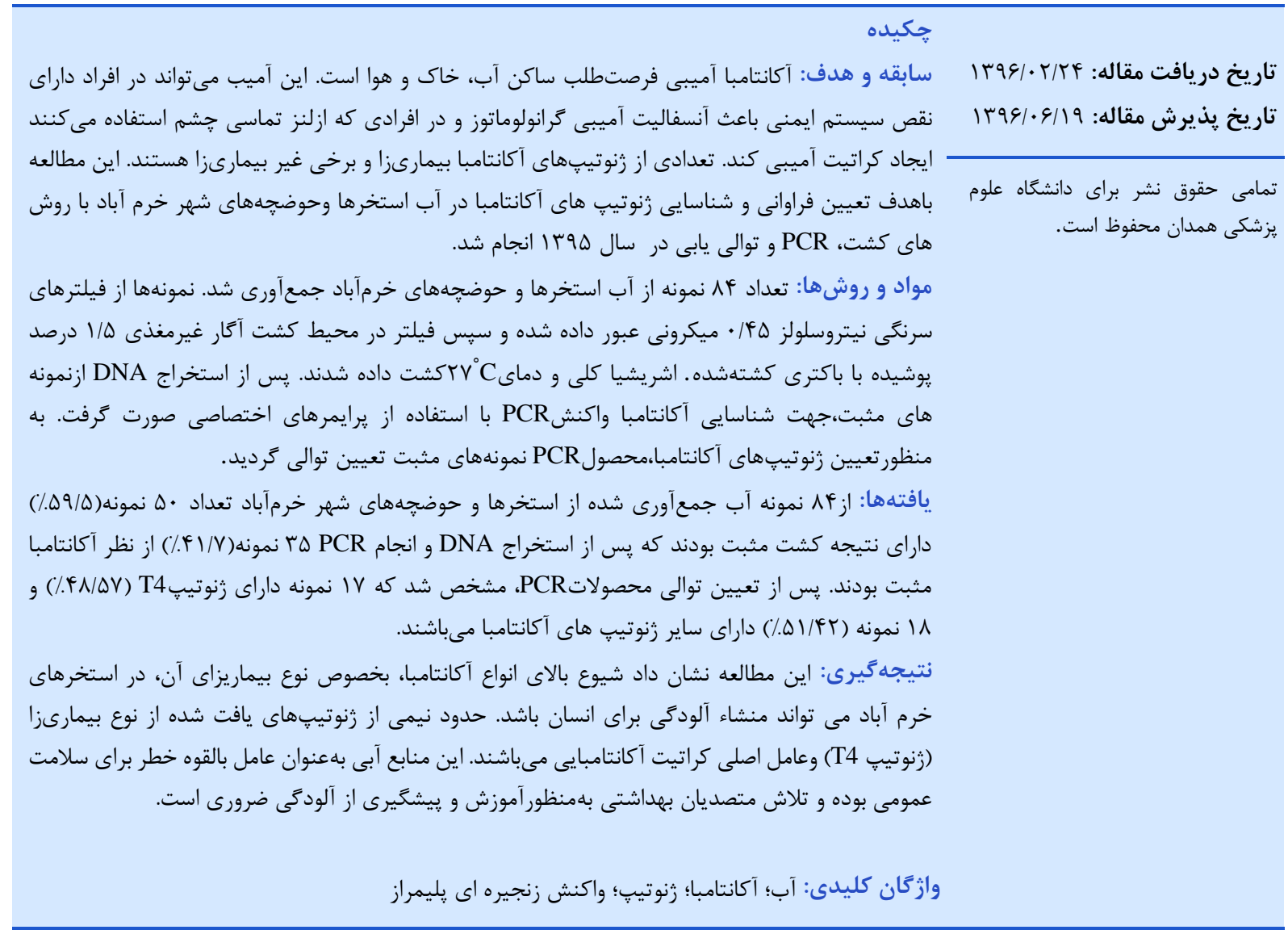

مقدمه - -

انتشار بسيار گسترده گونههاى بيمارىزا، ززارشهاى محدودى

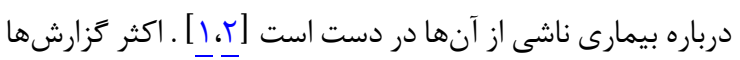

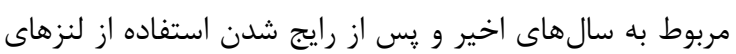

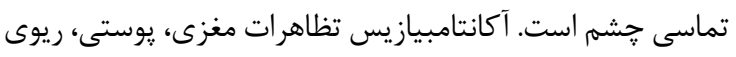

آكانتامبا از آميبهاى آزادزى است كه انتشار جهانى دارد و

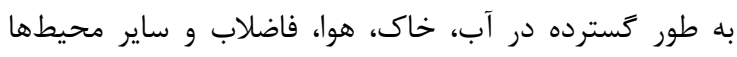

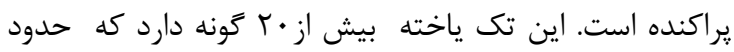

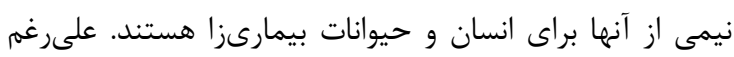


ايران نيز در اكثر موارد روشهاى تشخيصى بكار رفته، غير

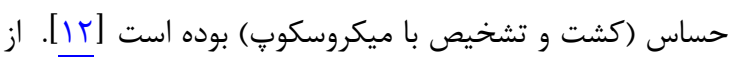

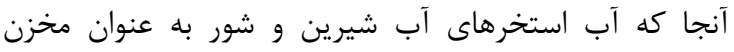

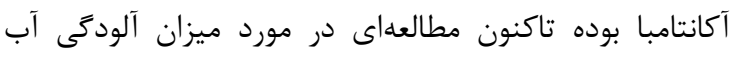
استخرها وحوضجههاى شهر خرمآباد به اين تك ياخته انجام نشده

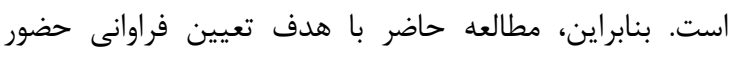

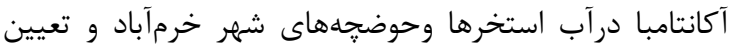
رنوتيب آميبهاى جدا شده انجام شد.

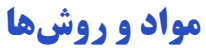 جمعآورى نمونه ها و كشت}

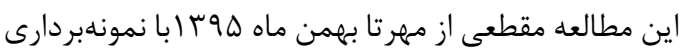

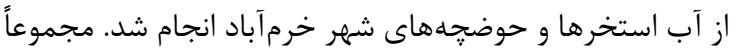

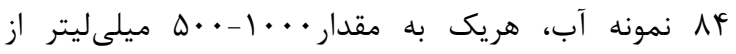

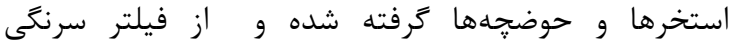

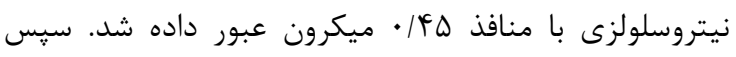

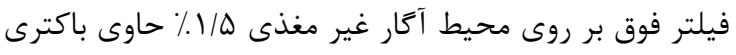

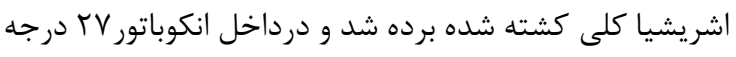

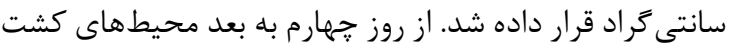

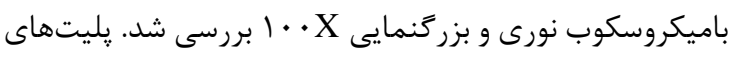

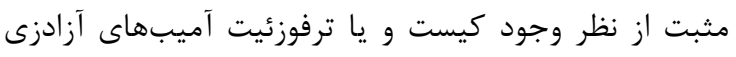

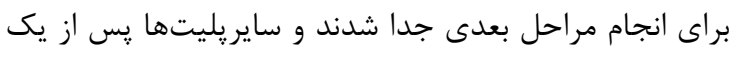

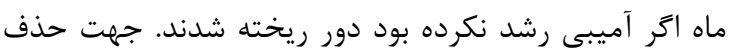

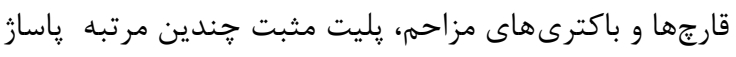

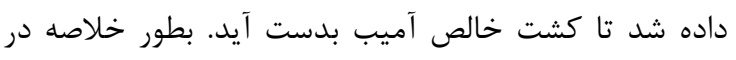

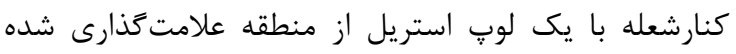

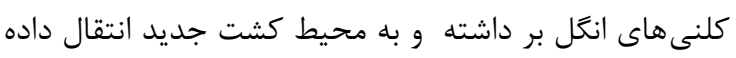

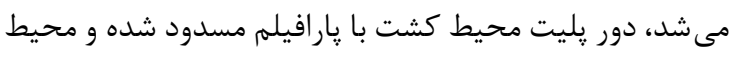

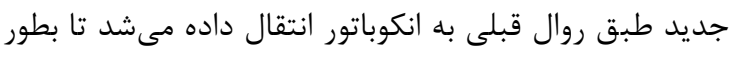
دقيق مجدداً مورد بر رسى قرارئيرد.

\section{اندازهحيرى شاخص هاى استاندارد آب}

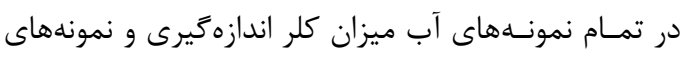

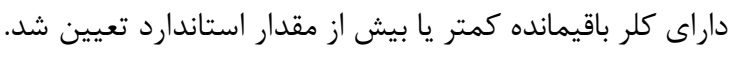

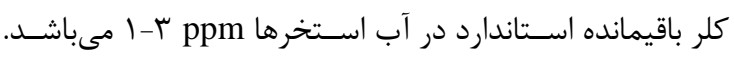

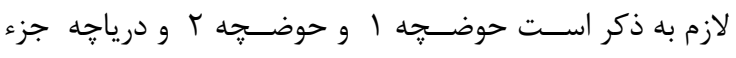

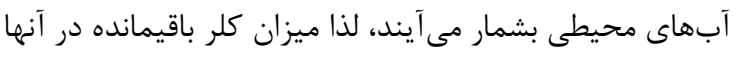

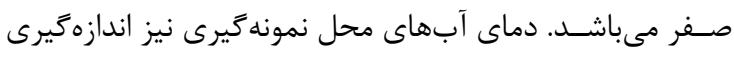

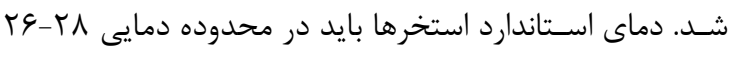

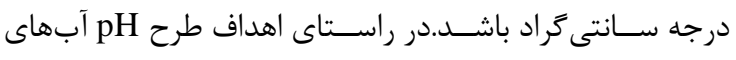

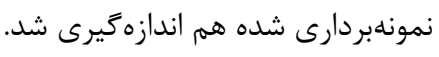

استخراج DNA

نمونهاى كشت مثبت جدا شده و ه سىسى بافرفسفات
و خشمى دارد كه سه مورد اول بطور عمده در بيماران دجار إنهار

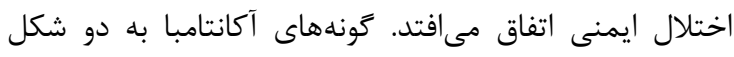

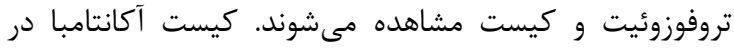

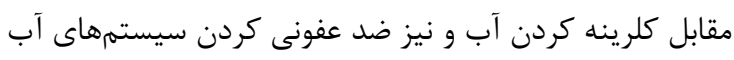

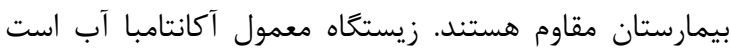

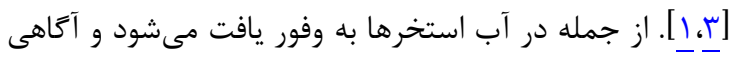

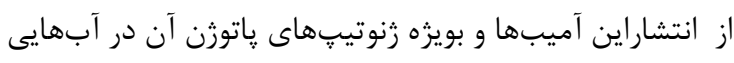

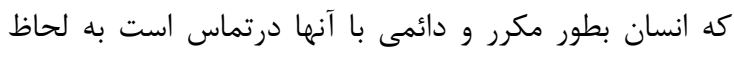

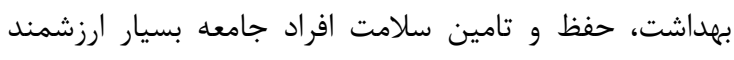

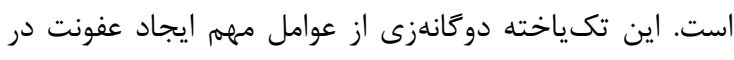

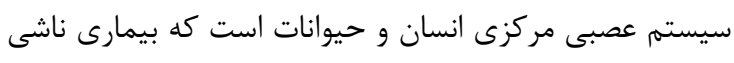

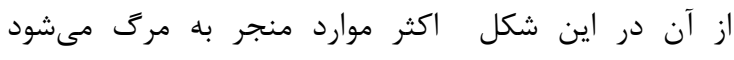

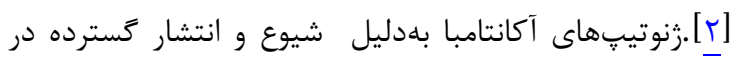

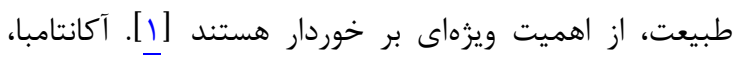

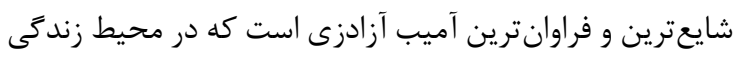

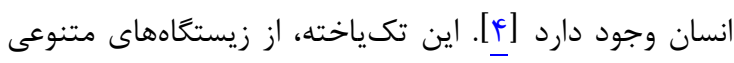

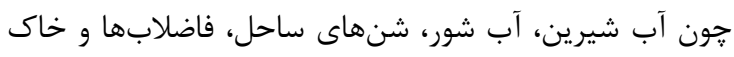

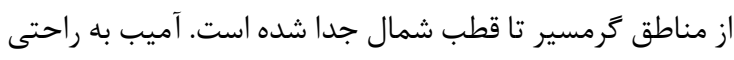

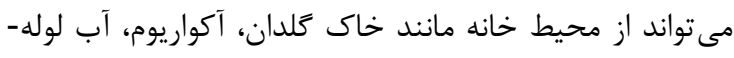

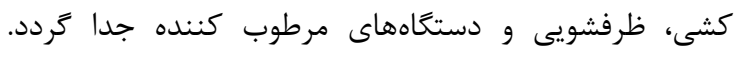



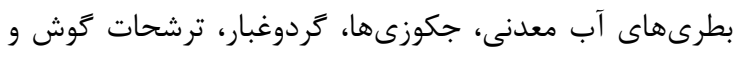

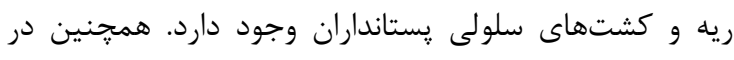

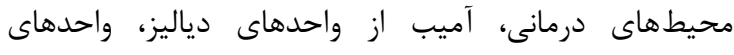

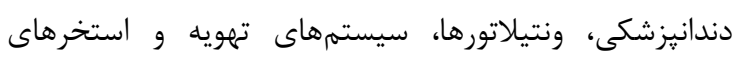

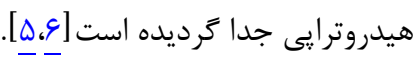

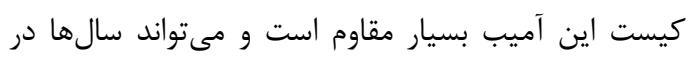

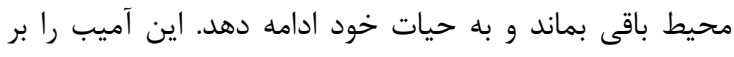

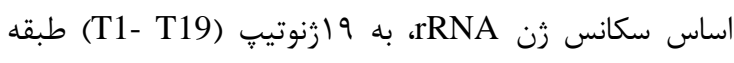

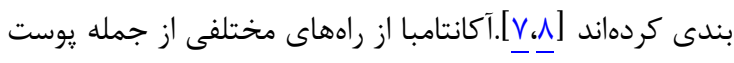

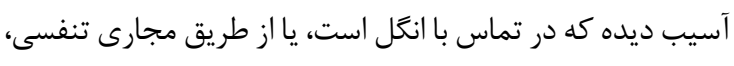

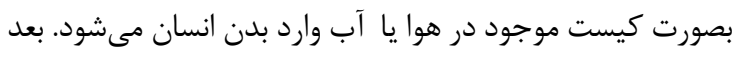

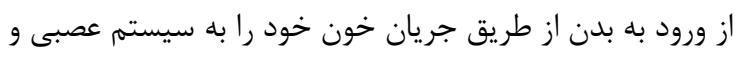

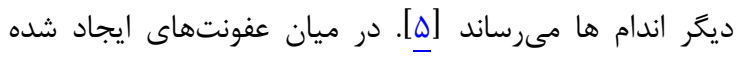

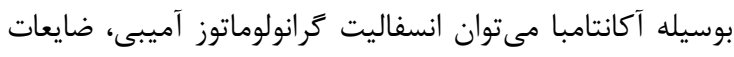

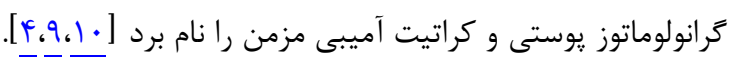

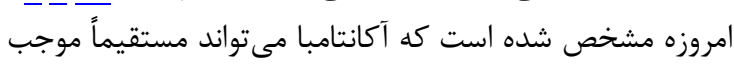

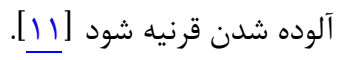

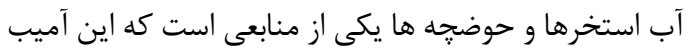

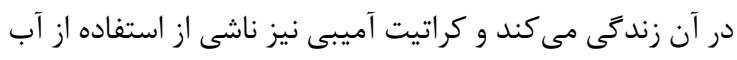

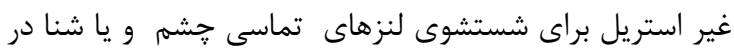

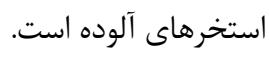

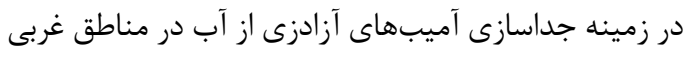

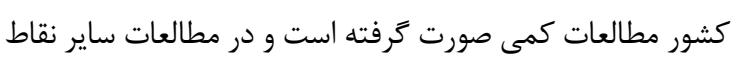


به شركت تكايوزيست ارسال كرديد. نتايج تعيين توالى با استفاده از

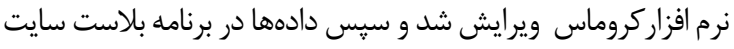
(National center for biotechnology Information) NCBI مورد تجزيه و تحليل قرار كرفت و زنوتيٍ ايزولهها مشخص گرديد.

\section{يافته ها شاخصهاى استاندارد آب}

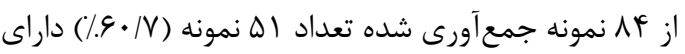

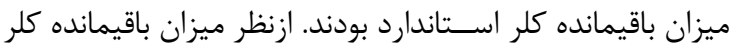

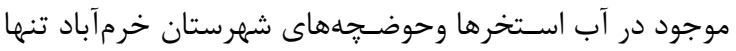

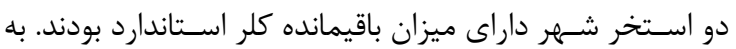

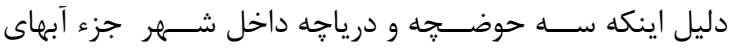

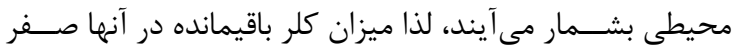

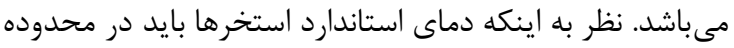

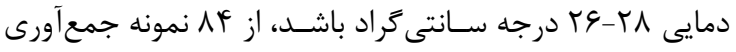

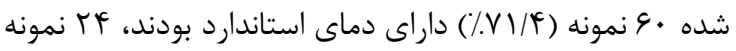

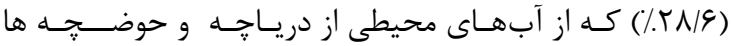

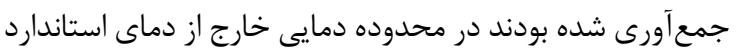

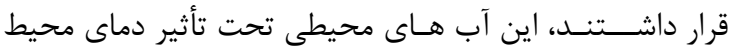

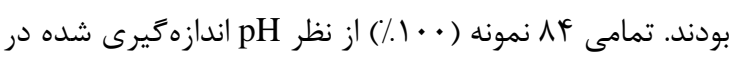

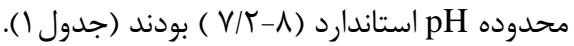

\section{نتا يج كشت و PCR}

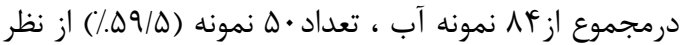

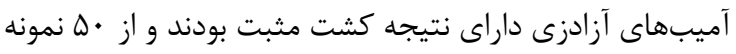

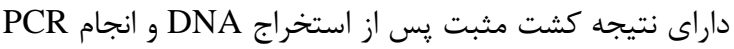

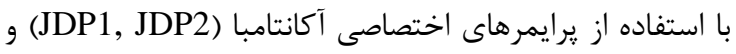

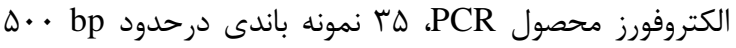
نشان دادند(جدول r ، شكل () ).

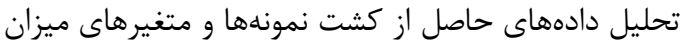

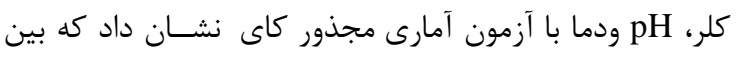

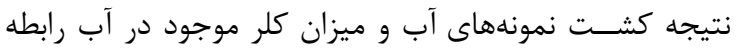

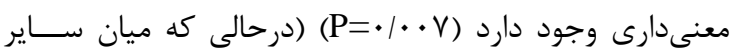

سالين روى محيط كشت ريخته شد. سيس با سرنگ ه ه سىسى

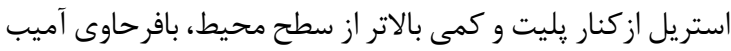

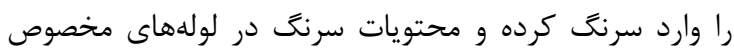

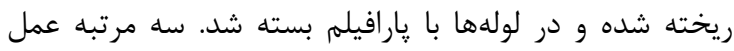

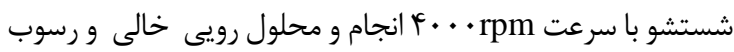
حاصل كه حاوى تعداد كافى آميب جهت استخراج

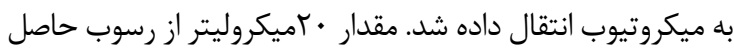

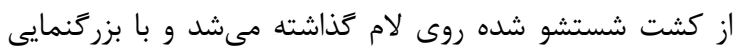
XX كيت شركت تكايوزيست (DynaBio TM DNA Extraction) و بر اساس يروتكل شركت سازنده استخراج شد.

\section{واكنش PCR}

واكنش زنجيرهاى يلىمراز (PCR) در حجم ه إن ميكروليتر با استفاده از يرايمرهاى اختصاصى آكانتامبا (JDP1, JDP2 )

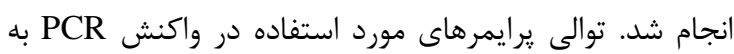
شرح زير مى باشد:

و JDP1: 5'-GGCCCAGATCGTTTACCGTGAA-3' JDP2: 5'- TCTCACAAGCTGCTAGGGAGTCA-3' .[Ir] واكنش PCR به همراه PNA نمونه آكانتامباى استاندارد اخذ شده از گروه انگلشناسى و قارجشناسى دانشخاه علوم

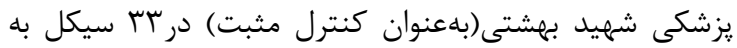
شرح زير انجام گرفت:

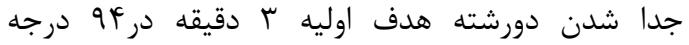

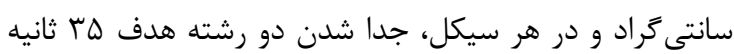

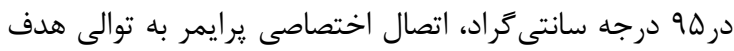

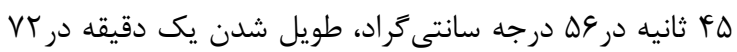

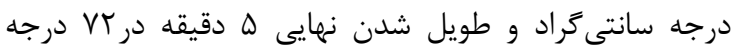

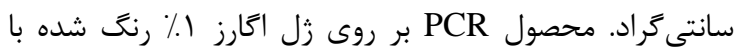

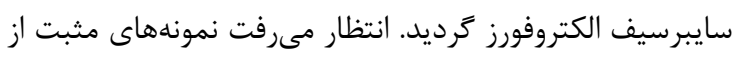

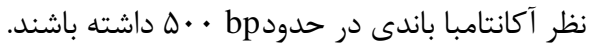

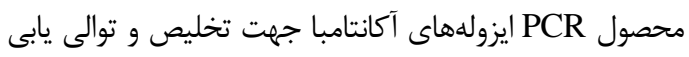

جدول ا: ميزان كلر، دما و pH آب استخرها و حوضجه هاى مورد مطالعه در شهر خرمآباد

\begin{tabular}{|c|c|c|c|c|c|}
\hline ميزان pH & دما بر حسب درجه سليسيوس & ميزان كلر باقيمانده برحسب ppm & تعداد نمونه & ن ام استخر & رديف \\
\hline 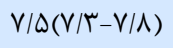 & $r \Lambda(T \vee-r \cdot)$ & $T / Y(Y-T / \Lambda)$ & $1 \cdot$ & 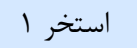 & 1 \\
\hline$V / F(V / T-V / \Lambda)$ & $r V(r Y-Y \wedge)$ & $\cdot \mid \Lambda(\cdot \mid \Delta-1)$ & $1 \cdot$ & استخر r & $r$ \\
\hline$V / F(V / F-V / A)$ & $r \varphi(r \Delta-r \Lambda)$ & $1(\cdot \mid \Delta-r)$ & 1. & استخر r & r \\
\hline$V / \varepsilon(V / G-V / \Lambda)$ & $r Q(r \Lambda-r \cdot)$ & $1 / 9(\cdot / \Delta-r / \Delta)$ & $1 \cdot$ & | استخر † & r \\
\hline$V / V(V / G-V / A)$ & $(Y V-r \cdot)$ & $\Gamma / Q(Y / Y-Y / \Lambda)$ & 1. & استخر ه & $\Delta$ \\
\hline$V / G(V / \Delta-V / \Lambda)$ & $r G(r \Delta-r q)$ & $1(1-Y / \Delta)$ & 1. & استخر 9 & 4 \\
\hline$V / F(V / T-V / \Delta)$ & $9(\Delta-9)$ & · & $\wedge$ & درياجه & v \\
\hline$V / F(V / T-V / \Delta)$ & $\Delta\left(\varphi^{*}-1 \cdot\right)$ & · & $1 \cdot$ & حوضجه 1 & $\wedge$ \\
\hline$V / T(V / T-V / \Psi)$ & $V(\Delta-4)$ & . & 9 & حوضجه r & 9 \\
\hline
\end{tabular}


جدول r: توزيع فراوانى آميبهاى آزادزى در آب استخرها وحوضجههاى شهر خرمآباددر سال ها9بر اساس روش PCRو كشت

\begin{tabular}{|c|c|c|c|c|c|c|}
\hline \multicolumn{2}{|c|}{ جمع } & \multicolumn{2}{|c|}{ نتيجه كشت } & \multicolumn{2}{|c|}{ مثبت } & \multirow{2}{*}{ نام استخر /حوضجه } \\
\hline درصد & 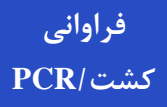 & (درصد)فراوانى & $\begin{array}{c}\text { PCR } \\
\text { (درصد)فراوانى }\end{array}$ & (درصد)فراوانى كشت & $\begin{array}{c}\text { PCR } \\
\text { (درصد)فراوانى }\end{array}$ & \\
\hline $1 \cdots$ & 1. & $\varphi(\varphi \cdot)$ & 1. & $f(\varphi \cdot)$ & $\cdot(\cdot)$ & استخر 1 \\
\hline $1 \cdots$ & 1 . & $1 \cdot(1 \cdots)$ & 1. & $\cdot(\cdot)$ & $\cdot(\cdot)$ & استخر r \\
\hline $1 \cdots$ & 1. & $\cdot(\cdot)$ & $1(1 \cdot)$ & $1 \cdot(1 \cdots)$ & $9(9 \cdot)$ & استخر r \\
\hline $1 \cdots$ & 1 . & $1 \cdot(1 \cdot \cdots)$ & $1 \cdot(1 \cdot \cdots)$ & $\cdot(\cdot)$ & $\cdot(\cdot)$ & استخر f \\
\hline $1 \cdots$ & 1. & $r(r \cdot)$ & $\Lambda(\Lambda \cdot)$ & $\Lambda(\Lambda \cdot)$ & $r(r \cdot)$ & استخر ه \\
\hline $1 \cdots$ & 1. & $\varphi(\varphi \cdot)$ & $V(V \cdot)$ & $F(F \cdot)$ & r & استخر 9 \\
\hline $1 \cdots$ & $\wedge$ & $\cdot(\cdot)$ & $r(r \Delta)$ & $\wedge(1 \cdot \cdots)$ & $q(V \Delta)$ & درياجه \\
\hline $1 \cdots$ & 1 . & $\cdot(\cdot)$ & $1(1 \cdot)$ & $1 \cdot(1 \cdot \cdots)$ & $9(9 \cdot)$ & حوضجه طبيعى 1 \\
\hline $1 \cdots$ & 9 & $\cdot(\cdot)$ & $\cdot(\cdot)$ & $9(1 \cdots)$ & $9(1 \cdots)$ & حوضجه طبيعى r \\
\hline $1 \cdots$ & $\Delta F$ & $\operatorname{Mr}(F \cdot / \Delta)$ & $p q(\Delta \Lambda / \mu)$ & 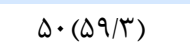 & $r \Delta(F \backslash / V)$ & مجموع \\
\hline
\end{tabular}
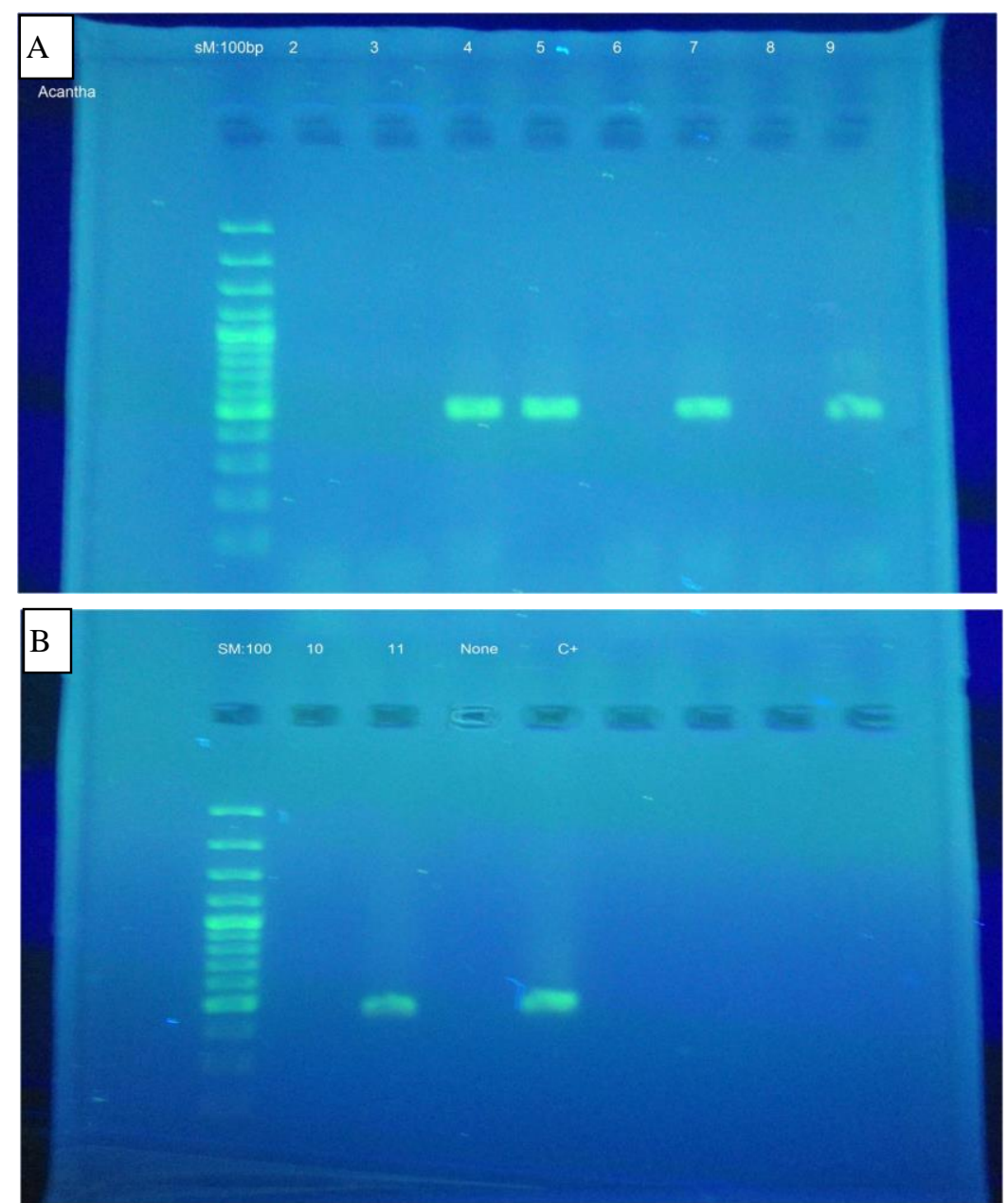

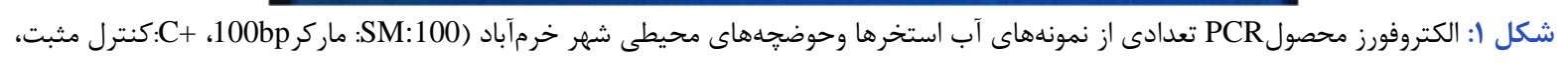

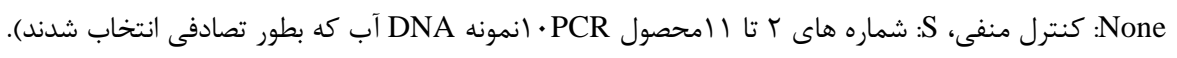

\section{توالى يابع و تعيين زنوتيب آكانتامبا}

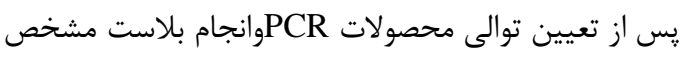

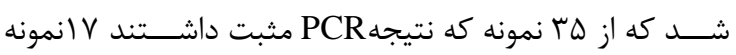

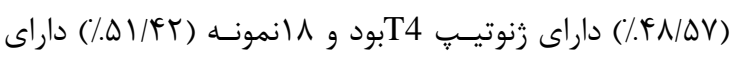

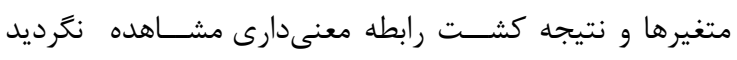

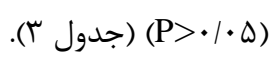

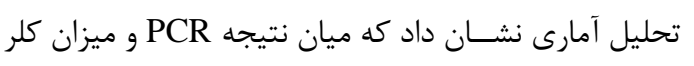

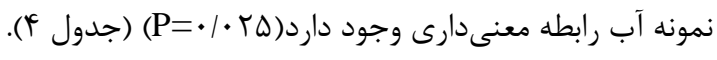


جدول ب: رابطه نتيجه كشت وميزان كلر موجود در نمونه آباستخرها و حوضجههاى شهر خرم آباد در سالهو

\begin{tabular}{|c|c|c|c|c|}
\hline P ارزش P & (درصد) تعداد & 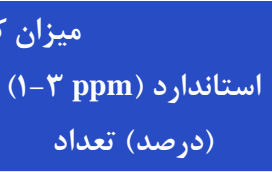 & غيراستاندارد & نتيجه كشت \\
\hline \multirow{3}{*}{$\cdot / \cdot V$} & $\operatorname{rF}(\mathcal{F} \cdot / \mathcal{F} \Lambda)$ & $r r(r q / r \Lambda)$ & $1(1 / T)$ & منفى \\
\hline & $\Delta \cdot(\Delta 9 / \Delta r)$ & $r \Delta(F \mid / \& \varphi)$ & $1 \Delta(\mid V / \wedge \Delta)$ & مثبت \\
\hline & $\Lambda F(1 \cdots)$ & $8 \wedge(\Lambda \cdot / 9 \Delta)$ & $19(19 / \cdot \Delta)$ & مجموع \\
\hline
\end{tabular}

جدول f: رابطه نتيجه PCR و ميزان كلر موجود در نمونه آب استخرها و حوضجه هاى شهر خرم آباد در سال هو

\begin{tabular}{|c|c|c|c|c|}
\hline ارزش & مجموع (درصد) تعداد & 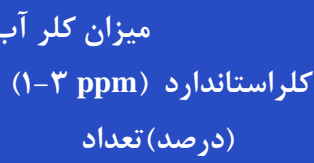 & كلر غير استاندارد & نتيجهAPCR \\
\hline \multirow{3}{*}{$\cdot 1 \cdot r \Delta$} & $F q(\Delta \wedge, r r)$ & $F \Delta(\Delta r / \Delta V)$ & $f(F / V \varepsilon)$ & منفى \\
\hline & $r \Delta(f \mid / q \varphi)$ & $r T(T V / T \Lambda)$ & $\mid r(\mid F / Y \Lambda)$ & مثبت \\
\hline & $\Lambda F(\mid \cdots)$ & $9 \Lambda(\Lambda \cdot / 9 \Delta)$ & $19(19 / \cdot \Delta)$ & مجموع \\
\hline
\end{tabular}

به دليل تغييرات در شكل كيست به علت شرايط موجود در

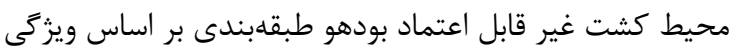

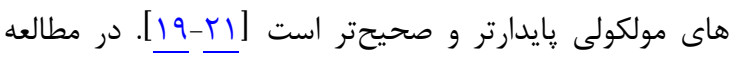
حاضر از روش PCR براى تشخيص وتاييد آكانتامبا در نمونههاى

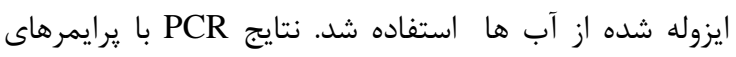

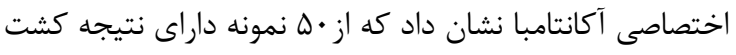

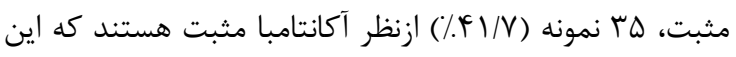

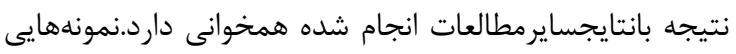

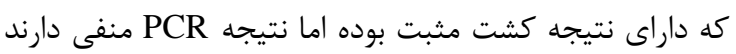

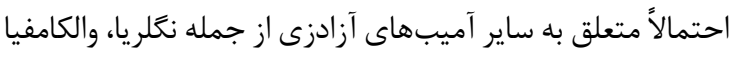
و بالاموثيا مى باشند كه تشخيص قطعى و افتراق آنها از آكانتامبا با استفاده از يرايمرهاى اختصاصى امكان يذير است.

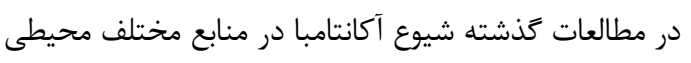

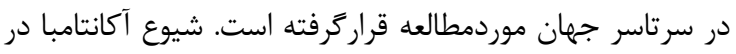

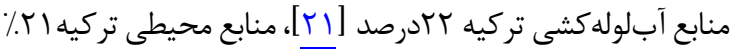

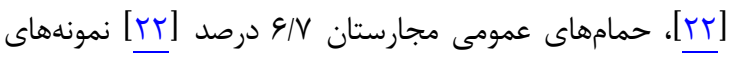

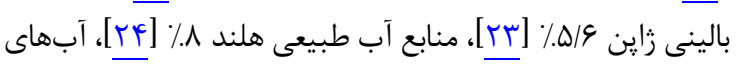

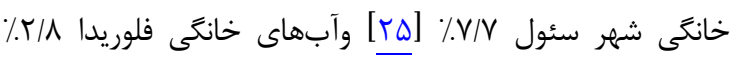

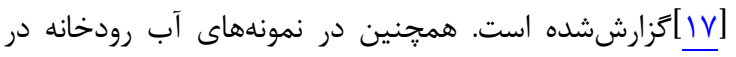

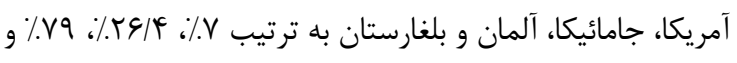

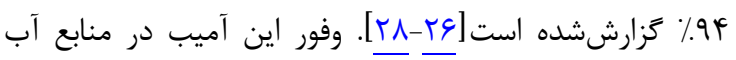

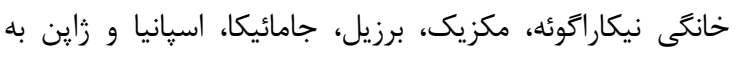

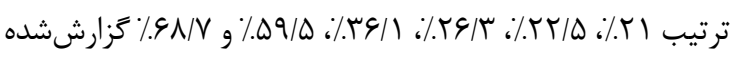

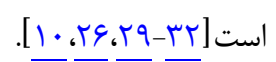

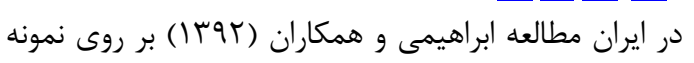

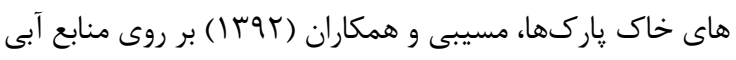

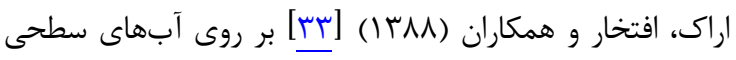

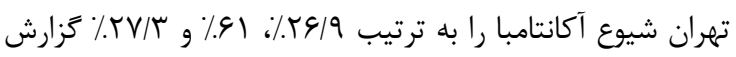

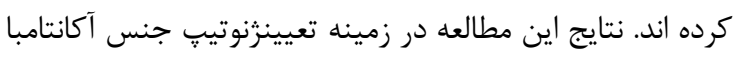

ســاير رنوتيبهاى آكانتامبا هســـتـندكه بدليل فقدان امكانات، امكان تعيين زنوتيٍ بقيه نمونه ها ميسر نشد.

نتايج حاصل ازمطالعه حاضر نشان مى دهد كه آميب آزادزى

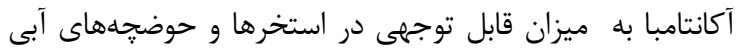

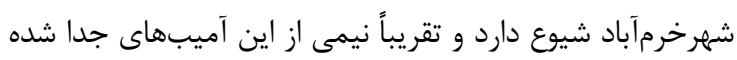

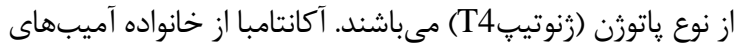

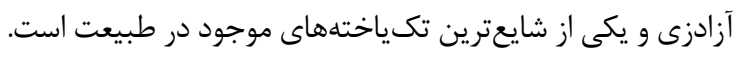
اين انكل فرصتطلب از محيطهاى مختلف جداشده ور دائل در ايران نيز

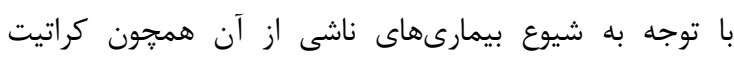

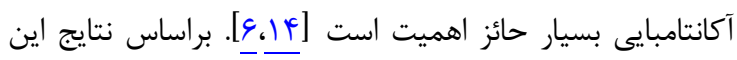

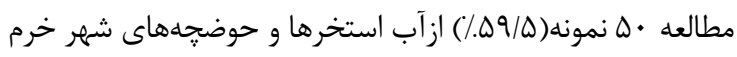

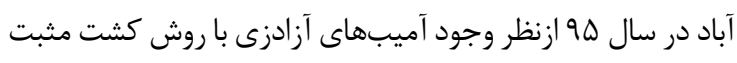

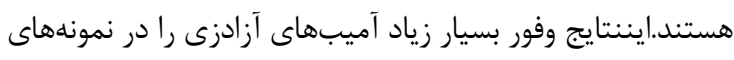

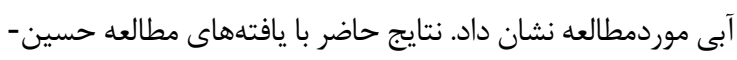

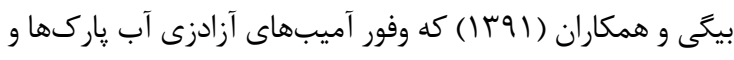
ميادين قزوين را • م درصد كزارش كردند [با]

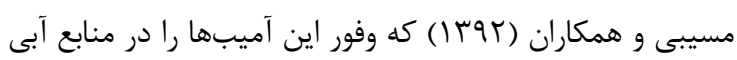

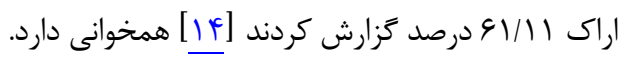

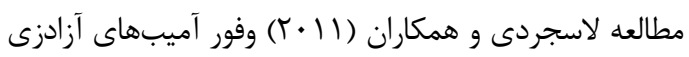
را در بخشهاى بسترى بيماران دجار نقص سيستم ايمنى در تهران

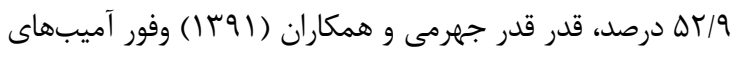

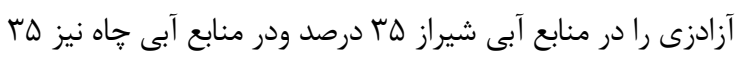

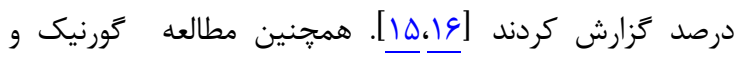

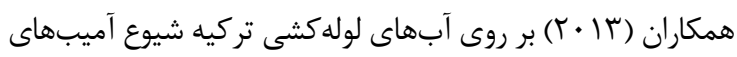

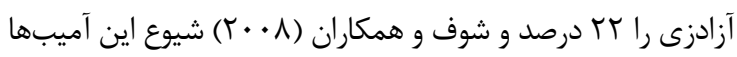

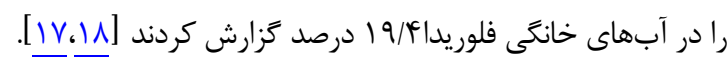

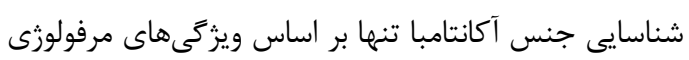




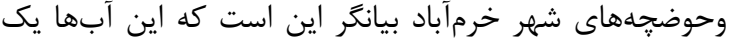

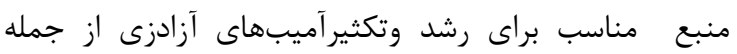

$$
\begin{aligned}
& \text { آكانتامبا هستند. }
\end{aligned}
$$

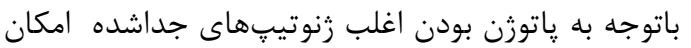

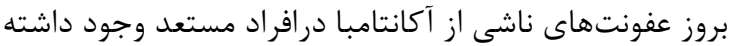

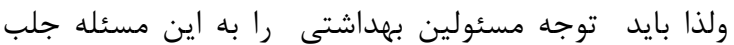
نمود.

از آنجا كه بين ميزان كلر باقيمانده و وفور آميب ارتباط

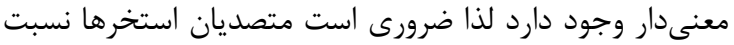
به كنترل ميزان كلر باقيمانده توجه ويزهاى داشته باشند.

\section{تشكر و قروراذى}

از معاونت محترم تحقيقات و فن آورى دانشعاه علوم يزشكى

همدان كه بخشى از هزينه اين تحقيق را تامين نمودند صميمانه

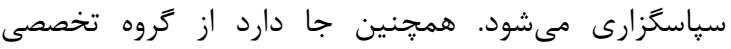

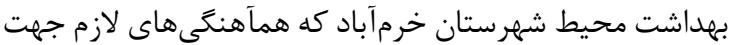

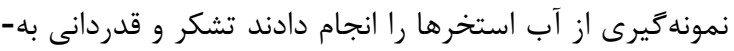

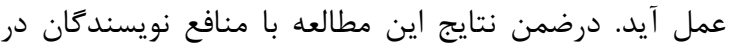
تضاد نمىباشد.

\section{REFERENCES}

1. Trabelsi H, Dendana F, Sellami A, Sellami H, Cheikhrouhou F, Neji S, et al. Pathogenic free-living amoebae: epidemiology and clinical review. Pathol Biol (Paris). 2012;60(6):399-405. PMID: 22520593 DOI: 10.1016/j.patbio.2012.03.002

2. Ramirez E, Campoy E, Matuz D, Robles E. Acanthamoeba isolated from contaminated groundwater. J Eukaryot Microbiol. 2006;53:S10-1. PMID: 17169014 DOI: 10.1111/j.1550-7408.2006.00156.x

3. Bunting LA, Neilson JB, Bulmer GS. Cryptococcus neoformans: gastronomic delight of a soil ameba. Sabouraudia. 1979;17(3):225-32. PMID: 394365

4. Marciano-Cabral F, Cabral G. Acanthamoeba spp. as agents of disease in humans. Clin Microbiol Rev. 2003;16(2):273307. PMID: 12692099

5. Schuster FL, Visvesvara GS. Free-living amoebae as opportunistic and non-opportunistic pathogens of humans and animals. Int J Parasitol. 2004;34(9):1001-27. PMID: 15313128 DOI: 10.1016/j.ijpara.2004.06.004

6. La Scola B, Boyadjiev I, Greub G, Khamis A, Martin C, Raoult D. Amoeba-resisting bacteria and ventilatorassociated pneumonia. Emerg Infec Dis. 2003;9(7):815-21. PMID: 12890321 DOI: 10.3201/eid0907.020760

7. Maghsood AH, Sissons J, Rezaian M, Nolder D, Warhurst D, Khan NA. Acanthamoeba genotype T4 from the UK and Iran and isolation of the T2 genotype from clinical isolates. $\mathrm{J} \mathrm{Med}$ Microbiol. 2005;54(Pt 8):755-9. PMID: 16014429 DOI: 10.1099/jmm.0.45970-0

8. Corsaro D, Venditti D. Phylogenetic evidence for a new genotype of Acanthamoeba (Amoebozoa, Acanthamoebida). Parasitol Res. 2010;107(1):233-8. PMID: 20411277 DOI: 10.1007/s00436-010-1870-6

9. Khan NA. Pathogenesis of Acanthamoeba infections. Microbial Pathogen. 2003;34(6):277-85. PMID: 12782480

10. Lorenzo-Morales J, Monteverde-Miranda CA, Jiménez C, Tejedor ML, Valladares B, Ortega-Rivas A. Evaluation of Acanthamoeba isolates from environmental sources in Tenerife, Canary Islands, Spain. Ann Agric Environ Med. 2005;12(2):233-6. PMID: 16457479

11. Clarke DW, Niederkorn JY. The pathophysiology of Acanthamoeba keratitis. Trends Parasitol. 2006;22(4):17580. PMID: 16500148 DOI: 10.1016/j.pt.2006.02.004

12. Rezaian M, Bagheri F, Farnia S, Babai Z. Isolation of

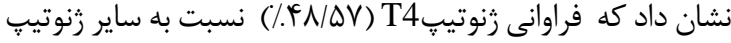

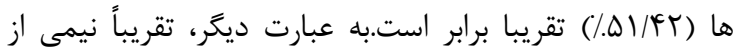

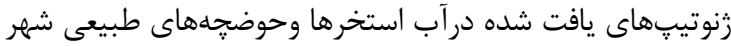

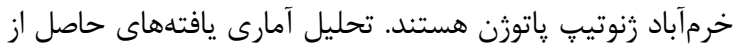
كشت و PCR حاكى از وجود رابطه معنى دار ميان نتيجه كشت و بCR رشد آكانتامبا و مثبت شدن نتيجه كشت يا PCR تاثير معكوسدارد. همجنين زنوتيڤهاى پاتوزن آكانتامبا مثل زنوتيڤ T4 در نمونههاى آب استخرها و حوضجههاى طبيعى شهر خرم آباد قدرت رشد بالايى دارند. وفور بالاى زنوتايي T4 در نمونههاى آب مورد بررسى حاكى از خطر بالقوه آن در ابتلا افرادى آنى

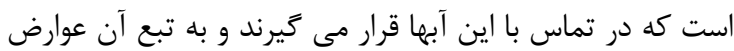

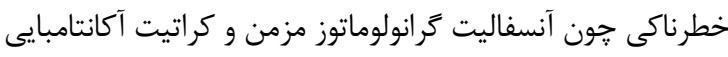
در افراد مستعد مىتواند ايجاد شود. اين مساله توجه مسئولان و متصديان بهداشتى در جهت اطلاع رسانى مناسب و برنامهريزى هاى آتى براى ييشخيرى و حذف آلودگى آبها را مى طلبد.

\section{نتيجه كيرى}

مشاهده ميزان قابل توجه آكانتامبا در نمونههاى آب استخرها

pathogenic amoeba (Naegleria and Acanthamoeba) From water sourcesand margin soils of reveirs and lakes in Kazerun. J School Public Health Institute Public Health Res. 2003;1(3):41-8.

13. Hosseinbigi B, Sahnesaraie MS, Alizadeh SA, Rasti S, Eftakhar M, Khosro-Shahi N, et al. Isolation and molecular identification of Acanthamoeba in surface stagnant waters of Qazvin. J Qazvin Univ Med Sci. 2012;16(3):26-32. [Persian]

14. Mosayebi M, Ghorbanzadeh B, Eslamirad Z, Ejtehadifar M, Rastad B. The Isolation and detection of Acanthamoeba in rural water sources of Arak, Iran. Med Lab J. 2014;7(4):6671. [Persian]

15. Ghadar S, Solhjoo K, Rohi R, Zia-Jahromi S. Isolation and identification of free living amoeba (Naegleria and Acanthamoeba) in Shiraz water resources by morphological criteria. J Jahrom Univ Med Sci. 2012;10(3):27.

16. Lasjerdi Z, Niyyati M, Haghighi A, Shahabi S, Biderouni FT, Taghipour N, et al. Potentially pathogenic free-living amoebae isolated from hospital wards with immunodeficient patients in Tehran, Iran. Parasitol Res. 2011;109(3):575-80. PMID: 21365453 DOI: 10.1007/s00436-011-2288-5

17. Shoff M, Rogerson A, Kessler K, Schatz S, Seal DV. Prevalence of Acanthamoeba and other naked amoebae in South Florida domestic water. J Water Health. 2008;6(1):99104. PMID: 17998610 DOI: $10.2166 /$ wh.2007.014

18. Górnik K, Kuźna-Grygiel W. Presence of virulent strains of amphizoic amoebae in swimming pools of the city of Szczecin. Ann Agric Environ Med. 2004;11(2):233-6. PMID: 15627330

19. Dávila ÁM. Epidemiología y diagnóstico de amebas de vida libre implicadas en salud humana. [Doctoral Dissertation]. Madrid: Universidad Complutense de Madrid; 2015.

20. Lorenzo-Morales J, Khan NA, Walochnik J. An update on Acanthamoeba keratitis: diagnosis, pathogenesis and treatment. Parasite. 2015;22:10. PMID: 25687209 DOI: $10.1051 /$ parasite/2015010

21. Jeong HJ, Yu HS. The role of domestic tap water in Acanthamoeba contamination in contact lens storage cases in Korea. Korean J Parasitol. 2005;43(2):47-50. PMID: 15951638

22. Kiss C, Barna Z, Vargha M, Török JK. Incidence and molecular diversity of Acanthamoeba species isolated from 
public baths in Hungary. Parasitol Res. 2014;113(7):2551-7. PMID: 24781024 DOI: 10.1007/s00436-014-3905-x

23. Rahman MM, Yagita K, Kobayashi A, Oikawa Y, Hussein AI, Matsumura T, et al. Genetic characterization of clinical Acanthamoeba isolates from Japan using nuclear and mitochondrial small subunit ribosomal RNA. Korean $J$ Parasitol. 2013;51(4):401-11. PMID: 24039282 DOI: 10.3347/kjp.2013.51.4.401

24. Lass A, Szostakowska B, Idzińska A, Chomicz L. The first genotype determination of Acanthamoeba potential threat to human health, isolated from natural water reservoirs in Poland. Parasitol Res. 2014;113(7):2693-9. PMID: 24770720 DOI: 10.1007/s00436-014-3925-6

25. Yu HS, Kong HH, Kim SY, Hahn YH, Hahn TW, Chung DI. Laboratory investigation of Acanthamoeba lugdunensis from patients with keratitis. Invest Ophthalmol Vis Sci. 2004;45(5):1418-26. PMID: 15111597

26. Lorenzo-Morales J, Coronado-Álvarez N, MartínezCarretero E, Maciver SK, Valladares B. Detection of four adenovirus serotypes within water-isolated strains of Acanthamoeba in the Canary Islands, Spain. Am J Trop Med Hyg. 2007;77(4):753-6. PMID: 17978083

27. Hoffmann R, Michel R. Distribution of free-living amoebae (FLA) during preparation and supply of drinking water. Inter J Hyg Environ Health. 2001;203(3):215-9. PMID: 11279817 DOI: $10.1078 / \mathrm{S} 1438-4639(04) 70031-0$

28. Ettinger MR, Webb SR, Harris SA, McIninch SP C, Garman
G, Brown BL. Distribution of free-living amoebae in James River, Virginia, USA. Parasitol Res. 2002;89(1):6-15. PMID: 12474037 DOI: $10.1007 / \mathrm{s} 00436-002-0707-3$

29. Leiva B, Clasdotter E, Linder E, Winiecka-Krusnell J. Freeliving Acanthamoeba and Naegleria spp. amebae in water sources of León, Nicaragua. Rev Biol Trop. 2008;56(2):43946. PMID: 19256418

30. Edagawa A, Kimura A, Kawabuchi-Kurata T, Kusuhara Y, Karanis P. Isolation and genotyping of potentially pathogenic Acanthamoeba and Naegleria species from tap-water sources in Osaka, Japan. Parasitol Res. 2009;105(4):1109-17. PMID: 19565268 DOI: $10.1007 / \mathrm{s} 00436-009-1528-4$

31. Magliano AC, da Silva FM, Teixeira MM, Alfieri SC. Genotyping, physiological features and proteolytic activities of a potentially pathogenic Acanthamoeba sp. isolated from tap water in Brazil. Exp Parasitol. 2009;123(3):231-5. PMID: 19646440 DOI: 10.1016/j.exppara.2009.07.006

32. Bonilla-Lemus P, Ramírez-Bautista GA, Zamora-Muñoz C, del Rocío Ibarra-Montes M, Ramírez-Flores E, HernándezMartínez MD. Acanthamoeba spp. in domestic tap water in houses of contact lens wearers in the metropolitan area of Mexico City. Exp Parasitol. 2010;126(1):54-8. PMID: 19995560 DOI: 10.1016/j.exppara.2009.11.019

33. Eftekhar M, Nazem ME, Haghighi A, Sharifi K, Nochi Z, Athari A. Detection of Acanthamoeba from fresh water using polymerase chain reaction. Res Med. 2009;33(1):43-6. 